\title{
Cooperación internacional
en la cuenca del Pacífico \\ La participación de Canadá en los organismos de cooperación de la Cuenca del Pacífico
}

$\mathrm{C}$ anadá se ha distinguido por ser uno de los países más activos en la Cuenca del Pacífico. Esto se ve reflejado en el hecho de que participa como miembro activo en los principales organismos de cooperación en la Cuenca del Pacífico, tales como la Conferencia de Comercio y Desarrollo del Pacífico (PAFTAD), el Consejo Económico de la Cuenca del Pacífico (PBEC), el Consejo de Cooperación Económica del Pacífico (PECC), el Foro de Cooperación Económica de Asia y el Pacífico (APEC), y el Foro Regional de ASEAN (ARF). Además, es compañero de diálogo de la Asociación de Naciones del Sudeste de Asia (ASEAN). ${ }^{1}$

La participación de Canadá en PAFTAD, aunque es a título personal, se registra desde sus inicios, cuando se organizó la primera reunión de este organismo por parte de Saburo Okita y Kiyoshi Kojima en enero de 1968, aunque sus propuestas datan de principios de la década. Así, debido a que PAFTAD es una organización de tipo académico, su aportación más importante ha sido la de propiciar la internacionalización del concepto de cooperación en el Pacífico y la realización de estudios e investigaciones independientes y objetivas sobre la cooperación económica en el área; tarea en la que han colaborado reconocidos economistas y académicos de origen canadiense, interesados en temas de economía y políticas relevantes para la región de Asia y el Pacífico.

* Investigador del Departamento de Estudios del Pacífico de la Universidad de Guadalajara.

ORCID http://orcid.org/0000-0003-0344-6895
Actualmente, forman parte del Comité Directivo Internacional de PAFTAD los profesores Wendy Dobson, de la Universidad de Toronto; Ralph Huenemann, de la Universidad de Victoria, y Edward English, de la Universidad Carleton, Ottawa. Este último se encargó de organizar la conferencia PAFTAD 22, en Ottawa, del 7 al 9 de septiembre de 1995, cuyo tema se refirió a Ambiente y desarrollo en el pacífico: problemas y opciones de política para economías dinámicas, que fue la más reciente celebrada en Canadá.

Por otra parte, en el PBEC, que fue la primera organización con perfil empresarial en la región y cuyos orígenes se remontan a 1964 (aunque constituida formalmente en 1967), Canadá ha participado desde su formación,junto con Australia, Japón, Nueva Zelanda y Estados Unidos. Uno de los principales objetivos que perseguía Canadá con su incorporación a este organismo fue avanzar en la construcción de nuevos escenarios que le permitieran una mayor diversificación, ya que tradicionalmente sus intereses estaban concentrados en Europa, específicamente en Gran Bretaña. Así, Canadá fue uno de los primeros países que reconocieron que, a pesar de las incertidumbres económicas, políticas y sociales de entonces, se estaba gestando un cambio que conduciría a una transformación paulatina hacia una nueva era, en la que los países del Pacífico tenderían a ser las fuerzas dominantes de la economía global. 
Canadá, al igual que el PBEC, reconoció desde entonces que el libre comercio y la inversión a través de mercados abiertos serían elementos esenciales de cualquier intento con miras a la cooperación económica regional, en donde el concepto de interdependencia jugaba un papel fundamental.

Con respecto a PECC, Canadá fue uno de los once países que asistieron a la primera reunión (PECC I) denominada "El Seminario de la Comunidad del Pacífico", efectuada en Canberra, Australia, en septiembre de 1980, a iniciativa de Masayoshi Ohira y Malcolm Fraser, entonces primeros ministros de Japón y Australia, respectivamente. Los demás países fueron: Australia, Corea, Estados Unidos, Filipinas, Indonesia, Japón, Malasia, Nueva Zelanda, Singapur y Tailandia. Para Canadá, PECC significa un vínculo de cooperación importante debido principalmente a que este organismo se propuso, desde sus inicios, el establecimiento de un mecanismo de cooperación para Asia y el Pacífico con cierta independencia, pero incluyente, que propiciara la integración guiada por las fuerzas del mercado, aunque tratando que fuera con el consenso más amplio posible, factores que para Canadá son fundamentales en sus objetivos de desarrollo propios. Y precisamente en busca de incorporar una mayor diversidad de puntos de vista en la definición del futuro de Canadá en Asia Pacífico, es que este país se involucró desde un principio en la dinámica generada en el seno de este organismo.

Así pues, una de las bases que dieron origen a este organismo fue el reconocimiento de la dificultad de que los gobiernos solos no pueden resolver los problemas relativos a las grandes diferencias entre ellos en términos culturales, de lenguaje, políticos, históricos, étnicos, etcétera, por lo que PECC se propuso proveer una red flexible e informal, libre de las restricciones impuestas por las formalidades de las relaciones entre los gobiernos, en la cual puedan interactuar los líderes empresariales, los académicos más destacados y los representantes gubernamentales de las economías miembros. Esta conformación tripartita es una característica única de PECC.
Canadá participa en este organismo por medio del Comité Canadiense para la Cooperación en el Pacífico (CANCPEC), el cual es administrado por la Fundación de Canadá para Asia y el Pacífico (APFC), entidad especializada en el estudio de temas sobre Asia y sus relaciones con Canadá. El representante de Canadá en PECC es el profesor Yuen Pau Woo, vicepresidente de investigación y economista en jefe de APFC.

La participación de Canadá en APEC, por otra parte, representa una de las vías más importantes de la actividad de este país en Asia Pacífico. También miembro de este organismo desde su formación en 1989, Canadá ha estado involucrado en éste no sólo por medio de la participación de instancias gubernamentales sino además por la comunidad empresarial, la academia y la sociedad no gubernamental, cuyas colaboraciones en los grupos de trabajo y comités han sido muy valiosas. Por ejemplo, un representante de Medio Ambiente en Canadá encabeza ahora el Comité de Desarrollo Sustentable de APEC; un representante de la Agencia de Inspección de Alimentos de Canadá preside el subcomité de Biotecnología; la comunidad empresarial tiene tres representantes en el Consejo Consultivo de Negocios en APEC (ABAC, por sus siglas en inglés). Merece especial mención este último, pues es fundamental el papel que desempeñan los miembros canadienses de ABAC, ya que coadyuvan al establecimiento de las directrices de la interacción de APEC con el sector privado, en su sentido más amplio, y proveen de consejos de política a su gobierno.

Por la relevancia que en la región Asia Pacífico ha adquirido APEC, Canadá ha puesto especial atención en su funcionamiento y ha enfocado una gran parte de sus esfuerzos para lograr una mayor liberalización del comercio y la inversión procurando reforzar el ambiente económico y social, no sólo en el ámbito exclusivo de APEC sino también a un nivel más global. Sin embargo, para el ciudadano promedio de este país no están muy claros los beneficios de la participación de Canadá en APEC, pues lo relacionan más con el uso de gases lacrimógenos para dispersar a los que protestaron durante la 
V Reunión de Líderes de APEC, llevada a cabo del 24 al 25 de noviembre de 1997 en Vancouver.

A pesar de esta situación, Canadá sigue confiando en APEC como el mecanismo más apropiado para avanzar en la promoción de una mayor cooperación económica y social en la región y que, a su vez, permita expandir las oportunidades de negocios para sus hombres de empresa. Pero ahora, después de haber fungido como organizador de las reuniones de APEC en 1997 y la experiencia que esto le representó, se preocupa más por asegurar que al perseguir el crecimiento en la región de Asia Pacífico se tenga también en consideración el desarrollo de los recursos humanos y la protección al medio ambiente. Por ello ha pugnado por la incorporación de sectores sociales interesados en proveer al proceso de APEC con fuentes de opiniones más diversificadas y haciendo hincapié en la importancia de una mayor participación de la sociedad civil en el proceso de APEC.

Por otro lado, el ARF, creado en 1994, es un organismo de cooperación en la Cuenca del Pacífico en materia de seguridad política y militar, del cual Canadá, junto con Australia, fue uno de sus primeros proponentes. La propuesta hecha por Canadá fue durante la Reunión Ministerial de ASEAN en Yakarta, en 1990; pero no prosperó en razón de que tenía como modelo el marco de cooperación en la materia existente en la entonces Comunidad Europea. Sin embargo, esto sentó las bases para que en reuniones posteriores se retomara el asunto tanto por Japón como por Estados Unidos, y al final también los países miembros de ASEAN y China, que eran los más renuentes, aceptaran la idea, aunque modificada de manera que respondiera a las necesidades específicas de la región y a la idea predominante en ASEAN de cómo debería ser una instancia de cooperación regional en esta materia.

La relevancia del ARF para Canadá estriba en que este organismo es la vía principal para la defensa de sus crecientes intereses económicos y políticos en la región. Esto se reconoció ampliamente en el Libro Blanco de la Defensa de 1994, mediante el cual se instruyó al Departamento de Defensa Nacional y a las

Fuerzas Canadienses a estrechar las relaciones en esta materia con la región Asia Pacífico. Esto dio por resultado que las actividades de las fuerzas canadienses se hayan ampliado gradualmente para incluir un programa regular de visitas e intercambios de tipo político y militar, en especial con la región del sudeste de Asia, lo cual es de particular relevancia considerando que la situación en el área de seguridad y defensa en la región es cada vez más compleja.

Entre los principales objetivos de esa mayor participación, destacan los que demuestran su compromiso con la seguridad regional; compartir su experiencia, habilidades y técnicas aprendidas durante décadas en áreas tales como el mantenimiento de la paz y el multilateralismo, y proveer de apoyo a los propósitos de la agenda de seguridad nacional de Canadá, en el sentido más amplio. Esto se refleja en la participación de las fuerzas armadas en eventos que tienen que ver con el mejoramiento de la confianza entre los países de la región, el entrenamiento para el mantenimiento de la paz, el auxilio en desastres, leyes sobre conflictos armados, educación militar, retiro de minas, etcétera. 
Finalmente, la participación de Canadá en las reuniones ministeriales de ASEAN, y su posterior incorporación al ARF, se dio en calidad de compañero de diálogo de este organismo. Esta relación entre Canadá y ASEAN se inició en febrero 1977, cuando por medio de la Secretaría de Relaciones Exteriores de Canadá se propuso un programa de asistencia para el desarrollo de ASEAN, y dicha relación se formalizó en 1981 con la firma del Acuerdo de Cooperación Económica ASEAN-Canadá, el cual entró en vigor a partir del 1 de junio de 1982. Este acuerdo proveyó de un mecanismo para la cooperación en materia industrial y comercial, además de la cooperación técnica necesaria, lo que se amplió en 1993 con la firma revisada del Acuerdo, el cual incorporó nuevas áreas de cooperación en materia de ciencia y tecnología, medio ambiente, desarrollo de mercados, entre otros.

Como compañero de diálogo de ASEAN, Canadá participa también en las Conferencias Posministeriales de ASEAN, el Comité Conjunto de Cooperación (el cual promueve y revisa las actividades de cooperación mutua), el Comité de Planeación y Seguimiento y el Consejo de Negocios ASEAN-Canadá, el cual coadyuva en la conducción y mantenimiento del diálogo entre ellos.

Así, Canadá mantiene una intensa actividad en la Cuenca del Pacífico, lo que demuestra la relevancia de la región, dado su carácter estratégico para los intereses canadienses no sólo en términos geopolíticos y comerciales sino también en la búsqueda de mejores condiciones de vida para el común de sus ciudadanos.

\section{Fuentes}

"About PECC", en www.pecc.net; "ASEAN-Canada Dialogue", "Overview of ASEAN-Canada Relations", en www.aseansec.org; "Canada's Involvement in APEC", "Canada's objectives in APEC", "APEC Workshop 1999. A Strategic Aproach to Canada's Role in APEC", en www.apecsec.org; PAFTAD Newsletters Núms. 10, November 1996, y 11, May 1998; "PBEC History", en www.pbec.org. Ti? 